\title{
C-Co-Fe (Carbon-Cobalt-Iron)
}

\section{Raghavan}

The review of this ternary system by [1988Ray] presented a liquidus projection, an isothermal section at $1000{ }^{\circ} \mathrm{C}$ for $\mathrm{Fe}$-rich alloys and polythermal sections at $\sim 5.5$ mass \% Co in the austenitic range and at 0.2, 0.7 and 4.75 mass $\%$ Co in the ferritic range. The computed phase equilibria of [1988Gui] and a reaction sequence were presented by [1994Rag]. The melting equilibria in the Fe-rich region under high pressure determined by [1994Koc] were reviewed in the update by [2002Rag]. Recently, [2008Had] redetermined the liquidus lines near the $\mathrm{Fe}$ corner and confirmed the presence of a minimum on the $(\mathrm{L}+\mathrm{fcc}+$ graphite $)$ univariant line.

\section{Binary Systems}

The C-Co phase diagram is a simple eutectic system with no stable intermediate phases. The $\mathrm{Fe}-\mathrm{C}$ phase diagram is in

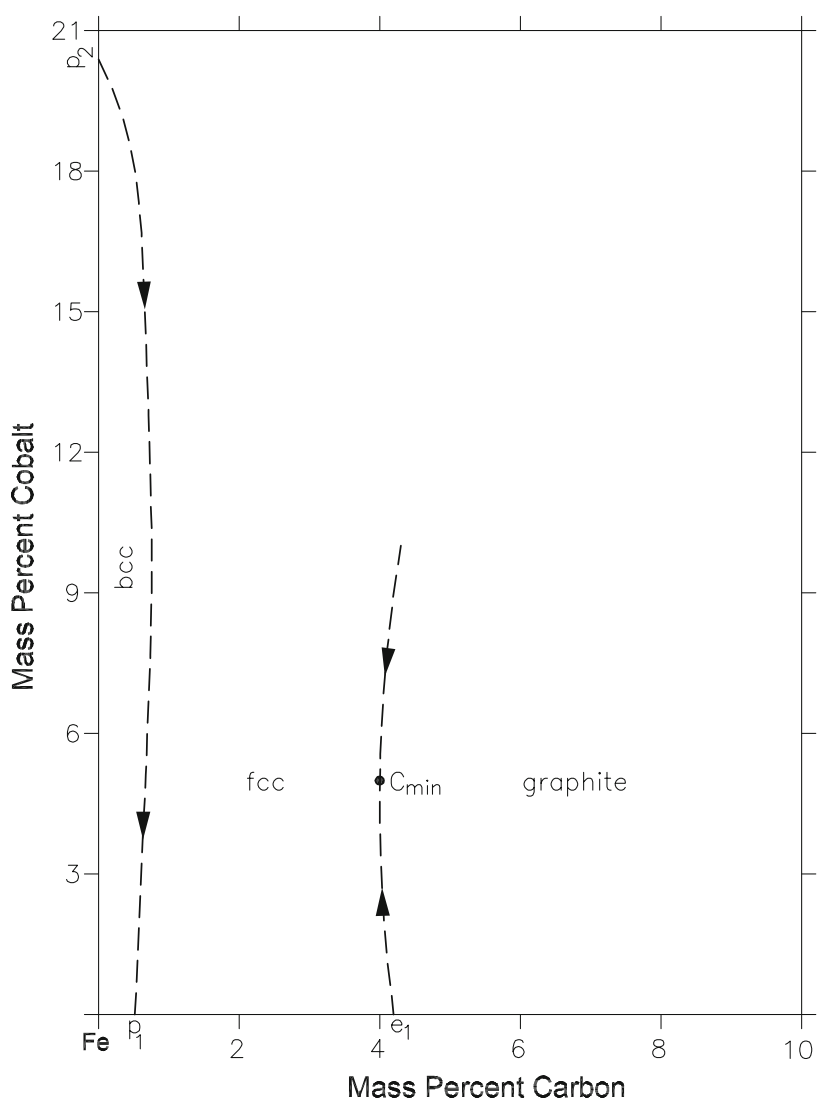

Fig. 1 C-Co-Fe liquidus projection near the Fe corner [2008Had] the form of a double diagram, corresponding to the metastable equilibrium with cementite $\left(\mathrm{Fe}_{3} \mathrm{C}\right)$ or the stable equilibrium with graphite (gr). In the stable diagram, the peritectic reaction at $1493{ }^{\circ} \mathrm{C}$ yields austenite (fcc). This is followed by the eutectic reaction at $1153{ }^{\circ} \mathrm{C}$, which yields ( $\mathrm{fcc}+\mathrm{gr}$ ). The eutectoidal decomposition of austenite occurs at $740{ }^{\circ} \mathrm{C}$, yielding [ferrite (bcc) $+\mathrm{gr}$ ]. The Co-Fe phase diagram is characterized by an extremely narrow solidification range. The continuous fcc phase forms through a peritectic reaction at $1499^{\circ} \mathrm{C}$ and is stable over a wide range of temperature. The fcc $\rightarrow$ bcc transformation temperature of $\mathrm{Fe}$ is initially raised by the addition of $\mathrm{Co}$, reaching a maximum at $985^{\circ} \mathrm{C}$. At $730{ }^{\circ} \mathrm{C}$, the bcc phase of equiatomic composition orders to a CsCl-type $B 2$ structure.

\section{Liquidus Projection of Fe-Rich Alloys}

With starting metals of $99.98 \% \mathrm{Fe}, 99.5 \% \mathrm{Co}$ and graphite, [2008Had] arc-melted under Ar atm eight Fe-rich ternary alloys with $\mathrm{Co}$ and $\mathrm{C}$ contents up to 10 and 4.2 mass $\%$ respectively. Differential thermal analysis was carried out at a cooling rate of $10{ }^{\circ} \mathrm{C}$ per min. Optical and scanning electron metallography and $\mathrm{x}$-ray powder diffraction were used to identify the phases. The partial liquidus projection for Fe-rich alloys constructed by [2008Had] is shown in Fig. 1. It is in agreement with that reviewed by [1988Ray] and that computed by [1988Gui]. The peritectic univariant line gently descends from the $\mathrm{Fe}-\mathrm{Co}$ side to the $\mathrm{Fe}-\mathrm{C}$ side. The eutectic univariant line shows a minimum at the critical point $\mathrm{C}_{\min }$ at $1150{ }^{\circ} \mathrm{C}$.

\section{References}

1988Gui: A.F. Guillermet, Thermodynamic Properties of the Fe-Co-C System, Z. Metallkd., 1988, 79(5), p 317-329

1988Ray: G.V. Raynor and V.G. Rivlin, C-Co-Fe, Phase Equilibria in Iron Ternary Alloys, Institute of Metals, London, 1988, p 140-142

1994Koc: Yu.A. Kocherzhinskii, O.G. Kulik, V.Z. Turkevich, and V.I. Vasilenko, Experimental Study of High Pressure Phase Equilibria in the Co-Fe-C System, Sverkhtverd. Mater., 1994, 16(3), p 6-11, in Russian

1994Rag: V. Raghavan, C-Co-Fe (Carbon-Cobalt-Iron), J. Phase Equilib., 1994, 15(4), p 416-418

2002Rag: V. Raghavan, C-Co-Fe (Carbon-Cobalt-Iron), J. Phase Equilib., 2002, 23(6), p 511-512

2008Had: F. Haddad, S.E. Amara, and R. Kesri, Liquidus Surface Projection of the Fe-Co-C Ternary System in the Iron Rich Corner, Int. J. Mater. Res., 2008, 99(9), p 942-946 